\title{
PREDICTION OF DELAMINATION SIZE IN DRILLING FIBER REINFORCED POLYMERIC COMPOSITE MATERIALS USING ARTIFICIAL NEURAL NETWORKS TECHNIQUE
}

\author{
A. I. Selmy, I. A. El-Sonbaty, U. A. Khashaba and A. A. Megahed \\ Mechanical Design and Production Engineering Department, Faculty of Engineering, \\ Zagazig University, P.O. Box 44519, Zagazig, Egypt.
}

\begin{abstract}
Delamination is a well-recognized problem associated with drilling fiber reinforced composite materials (FRCMs). The most noted problems occur as the drill enters and exits the FRCM. A method based on the artificial neural networks (ANNs) technique was used to predict delamination size resulting from drilling glass fiber reinforced epoxy (GFRE) laminates at both drill entry and exit sides of the hole. The experimental work that was performed to provide the data used to develop the required ANNs was presented in [1]. From the statistical analysis, using correlation coefficients between the target and the output values from the ANN, it is concluded that the obtained ANNs can be used effectively to model and predict delamination size at both drill entry and exit sides.

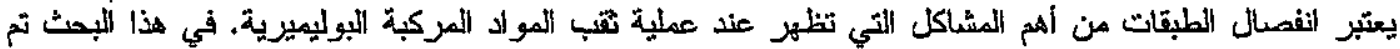

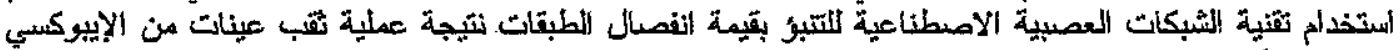

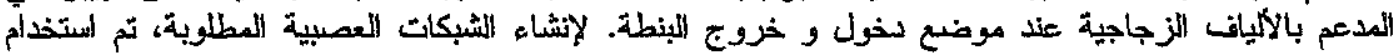

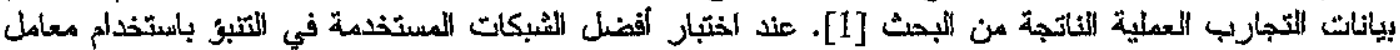

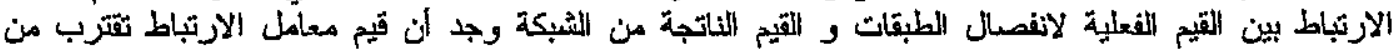

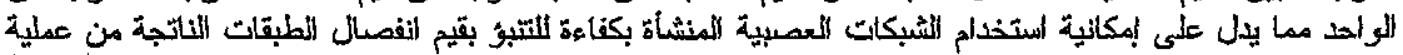

Keywords: Prediction, Delamination size, Drilling, Composite Materials, Artificial Neural Networks (ANNs).

\section{INTRODUCTION}

Machining composite materials is a rather complex task owing to its heterogeneity, heat sensitivity, and to the fact that reinforcements are extremely abrasive. Conventional machining methods should be adapted in such a way that they diminish thermal and mechanical damage. Drilling is a frequently practiced machining process in industry owing to the need for component assembly in mechanical pieces and structures. The drilling of laminate composite materials is significantly affected by the tendency of these materials to delaminate and the fibers to bond from the matrix under the action of machining forces (thrust force and torque). The presence of delamination reduces the stiffness and strength of a laminate and hence its load carrying capacity. Delamination can often be the limiting factor in the use of composite materials for structural applications, particularly when subjected to compressive, shear and fatigue type of loads and when exposed to moisture and other aggressive environments over a long period of time.

Artificial neural networks (ANNs) have recently been introduced into the field of polymer composites. Inspired by the biological nervous system, ANNs can be used to solve a wide variety of complex scientific and engineering problems. Like their biological counterparts, ANNs can learn from examples, and therefore can be trained to find solutions of the complex non-linear, multi-dimensional functional relationships without any prior assumptions about their nature; further, the network is built directly from experimental data by its self-organizing capabilities [2].

Ho-Cheng and Dharan [3] presented an analysis of delamination during drilling of composite materials using fracture mechanics approach. The analysis predicts an optimal thrust force (defined as the minimum force above which delamination is initiated) as a function of drilled hole depth and material properties. Jain and Yang [4] proposed an analytical model based on fracture mechanics to predict critical thrusts and feed rates at which the delamination crack begins to propagate at different ply levels for unidirectional laminates. Jain and Yang [5] demonstrated that the critical thrusts and feed rates obtained for unidirectional laminates can be conservatively used for multi-directional laminates.

Stone and Kishnamurthy [6] developed a thrust force controller to minimize the delamination associated 


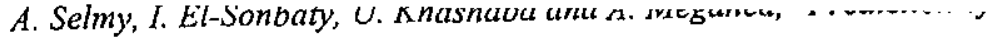

with drilling in graphite-epoxy laminate. A neural network control scheme was implemented which required a neural network identifier to model the drilling dynamics and a neural network controller to learn the relationship between feed rate and the desired thrust force. The robustness of the controller was demonstrated by varying some of the drilling parameters, spindle speed and drill diameter. Sadat [7] used an analytical approach to predict the delamination load (the trust force that causes delamination at a given ply location) in a drilling of graphite/ epoxy multilayered (angle-ply) composite laminates. In his work, it was assumed that delamination was caused by the thrust force of the drill, and a relation for delamination load as a function of material properties and uncut plies thickness was determined. Enemuoh et al [8] used an intelligent sensor fusion technique based on artificial neural network to predict on-line delamination during drilling of an advanced fiber composite beam (AS4/PEEK). The fusion model included two drilling parameters (feed rate and cutting speed), two drilling conditions (tool material and tool geometry) and two sensors (thrust force and acoustic emission).

Chakraborty [9] aimed at developing an artificial neural network model for detection of extent of delamination, its shape and location in a graphite/epoxy composite laminate using natural frequencies as inputs and corresponding size, shape and location of delamination as outputs of the network. Hundreds of finite element models have been run to generate natural frequencies up to ten modes for various combinations of size, shape and location of an embedded delamination in a laminate and these data have been used to train a back propagation neural network for future prediction of delamination in the laminate.

Sardinias et al [10] proposed a multi-objective optimization of the drilling process of a laminate composite material. Two mutually conflicting objectives are optimized: material removal rate, which represents the productivity; and delamination factor, which characterizes the superficial quality. A micro-genetic algorithm was implemented to carry out the optimization process. An a posteriori approach was used to obtain a set of optimal solutions. Finally, the obtained outcomes were arranged in graphical form (Pareto's front) and analyzed to make the proper decision for different process preferences.

Srinivasa Rao et al [11] used the multi-variable linear regression analysis to make the correlation between the delamination factor and the drilling parameters; feed rate, spindle speed and drill diameter, when drilling glass/epoxy woven mat cross-ply laminates. Karnik et al [12] predicted the delamination factor at the entrance side of drilled CFRP plates, using the multilayer feed forward ANN model trained by errorback propagation training alyorithm, with spindle speed, feed rate and point angle as the inputs to the developed ANN. Drilling experiments are conducted as per full factorial design using cemented carbide (grade K20) twist drills that serve as input-output patterns for ANN training.

This paper summarizes an approach for prediction of delamination size, both at drill entry and exit sides, resulting from drilling GFRF specimens, using the feed-forward artificial neurial networks (ANNs) technique trained with the back-propagation routine. The inputs to the neural network were drill diameter, spindle speed, feed, drill pre-ıvear, thrust force, and torque.

\section{DATA FOR DEVELOPMENT OF ANNS}

Artificial neural network algorithms are regarded as multivariate nonlinear analyitical tools capable of recognizing patterns from noisy complex data and estimating their nonlinear relationships. Their major advantages include superior learning, noise suppression, and parallel data processing capabilities [13]. Further, the network s built directly from experimental data by its self-organizing capabilities [2].

Experimental work was performed in order to obtain the data required to train, validate and test the developed ANNs. E-glass fiber reinforced epoxy (GFRE) woven roving composite specimens were manufactured using hand lay-up technique [14]. Specimens were machined using cemented carbide drills with two diameters $\Phi 8$ and $\Phi 13 \mathrm{~mm}$. The workpieces were drilled with five spindle speeds, five feeds and five drill pre-wear values (fresh drill plus four artificially introduced pre-wear values) with a backing plate has a center hole of $26 \mathrm{~mm}$ under dry cutting conditions. The details about the experimental work and the specification of the GFRE specimens were presented in [1]. At the end of the experimental work there were 250 holes (125 holes for each drill diameter) plus 25 holes machined with cutting conditions different from that of the experimental work for the purpose of testing the developed neural networks for generalization.

\section{RESULTS AND DISCUSSION}

In order to develop the required neural networks, from all of the holes that were machined in the experimental work, holes were selected randomly as; 200 holes for training pattems, 50 holes for cross validation patterns (which were used as a training stoppage criterion [15]), and 25 holes were used as test patterns.

All of the developed ANN/s are of multi-layer perceptron type and trained using the backpropagation routine $[16,17]$. A NeuroSolutions software (version 5) [18] was used in the training, 
validating and testing process of the developed neural networks. For training, a value of 0.7 was selected for the momentum term, a starting value of 1.0 was assigned for the learning rate, and maximum epochs of 40,000 were chosen with batch weight update method.

\subsection{ANNs for Thrust Force and Torque Prediction}

Among the inputs to the ANNs for delamination size prediction, there are thrust force and torque. Thus, before using the developed networks, thrust force and torque generated during the drilling process should be predicted in order to eliminate the need for measuring each of thrust force and torque at every prediction process of delamination size.

To obtain the best neural network structure, nineteen neural networks were developed by changing both of the number of hidden layers and the number of hidden units within each hidden layer.

\section{(1) ANNs for thrust force prediction}

Figure 1 shows the schematic diagram of the neural net for predicting the thrust force $\left(F_{t}\right)$. Four inputs were fed to the network; spindle speed, feed, drill pre-wear and drill diameter.

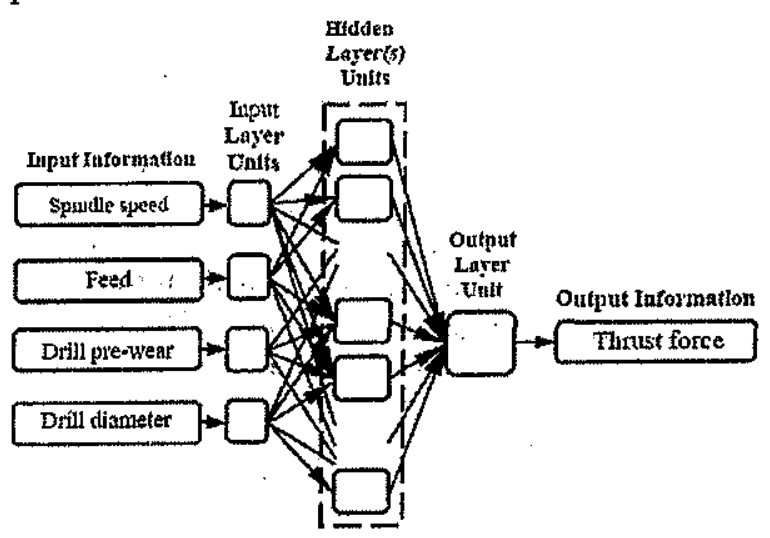

Fig. 1 Schematic diagram of the neural network for predicting thrust force.

Table 1 represents the tried neural networks that were used for the prediction of $F_{s}$. From the Table it can be seen that the best neural network for predicting $F_{t}$ is the net which has the structure of 4 input units, 4 hidden units in first hidden layer, 6 hidden units in second hidden layer and one output node $\left(F_{t}\right)$ where its test data set error is the lowest value $\left(685.92 \mathrm{~N}^{2}\right)$. Fig. 2 shows the relationship between the measured and the predicted values of $F_{t}$ for this best net, including the results of training, validation and test data sets.

\section{(2) ANNs for Torque Prediction}

Figure 3 shows the schematic diagram of the neural net for predicting the torque (T). Four inputs were fed to the network; spindle speed, feed, drill pre-wear and drill diameter.

Table 1 Trials for the ANNs for predicting thrust force

\begin{tabular}{|c|c|c|c|c|}
\hline No. & $\begin{array}{c}\text { Network } \\
\text { Structure }\end{array}$ & $\begin{array}{c}\text { Training } \\
\text { Set MSE } \\
\left(\mathbf{N}^{2}\right)\end{array}$ & $\begin{array}{c}\text { Validation } \\
\text { Set MSE } \\
\left(\mathbf{N}^{2}\right)\end{array}$ & $\begin{array}{c}\text { Test Set } \\
\mathbf{M S E} \\
\left(\mathbf{N}^{2}\right)\end{array}$ \\
\hline 1 & $4-2-1$ & 3064.43 & 4215.79 & 2046.56 \\
\hline 2 & $4-4-1$ & 852.80 & 1641.96 & 3766.13 \\
\hline 3 & $4-6-1$ & 413.93 & 1093.04 & 1260.83 \\
\hline 4 & $4-8-1$ & 311.79 & 870.57 & 1349.23 \\
\hline 5 & $4-10-1$ & 225.76 & 764.06 & 2869.18 \\
\hline 6 & $4-12-1$ & 163.20 & 663.40 & 3501.07 \\
\hline 7 & $4-2-2-1$ & 1891.31 & 3110.48 & 6460.15 \\
\hline 8 & $4-2-4-1$ & 1893.41 & 3107.27 & 4484.77 \\
\hline 9 & $4-4-2-1$ & 635.94 & 1040.81 & 1130.97 \\
\hline 10 & $4-4-4-1$ & 519.75 & 870.50 & 1246.73 \\
\hline 11 & $4-4-6-1 *$ & 440.94 & 1090.87 & 685.92 \\
\hline 12 & $4-6-4-1$ & 285.34 & 864.77 & 1223.04 \\
\hline 13 & $4-6-6-1$ & 304.80 & 760.32 & 939.15 \\
\hline 14 & $4-6-8-1$ & 307.11 & 653.40 & 1071.55 \\
\hline 15 & $4-8-6-1$ & 277.69 & 550.78 & 1654.97 \\
\hline 16 & $4-8-8-1$ & 257.96 & 643.75 & 3948.74 \\
\hline 17 & $4-8-10-1$ & 191.12 & 702.85 & 1275.64 \\
\hline 18 & $4-10-8-1$ & 230.48 & 510.98 & 2408.76 \\
\hline 19 & $4-10-10-1$ & 133.48 & 449.47 & 4481.59 \\
\hline
\end{tabular}

* The best network structure.

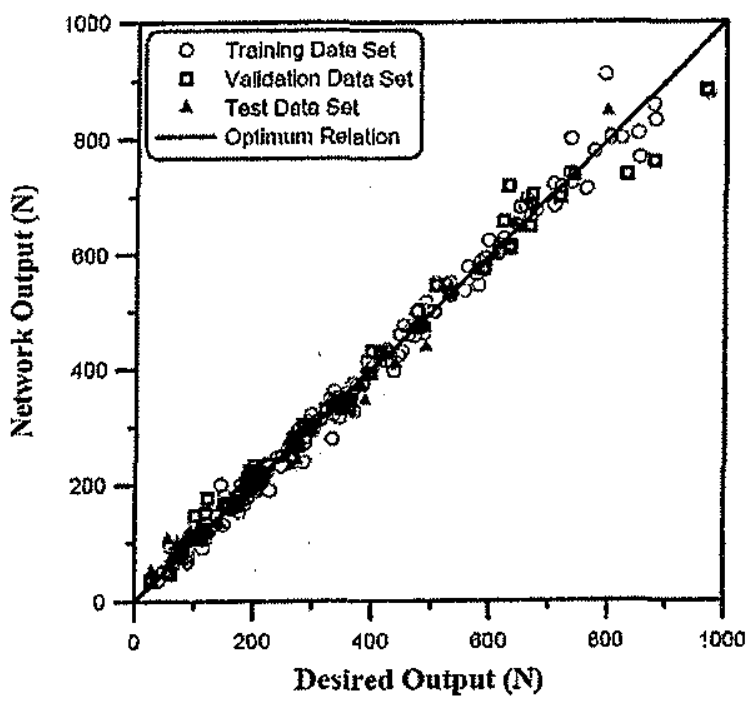

Fig. 2 Relationship between actual (desired) and predicted (output) values of the best obtained network for predicting thrust force.

Table 2 represents the tried neural networks that were used for the prediction of T. From the Table it can be seen that the best neural network for predicting $T$ is the net which has the structure of 4 input units, 2 hidden units in first hidden layer, 2 hidden units in second hidden layer and one output node $(\mathrm{T})$ where 


\section{ll.}

its test data set error is the lowest value (0.0094 $(\mathrm{N} . \mathrm{m})^{2}$ ).

Fig. 4 shows the relationship between the measured (target) and the predicted (output) values of $T$ for this best net, including the results of training, validation and test data sets.

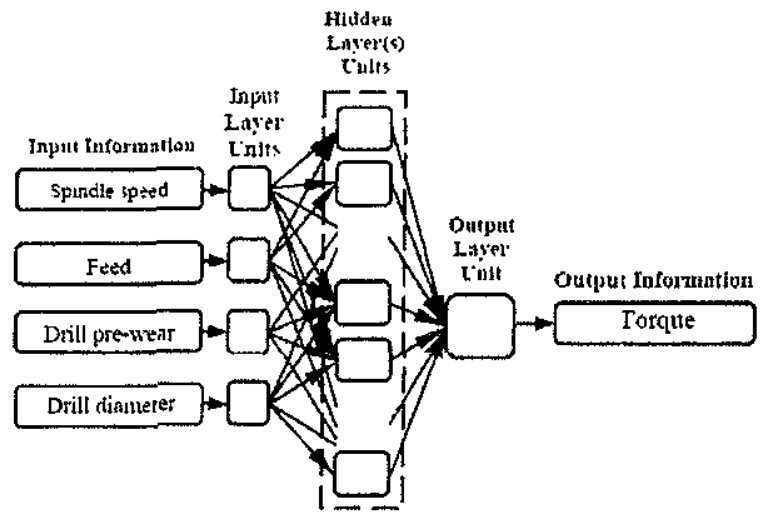

Fig. 3 Schematic diagram of the neural network for predicting torque.

Table 2 Trials for the ANNs for predicting torque

\begin{tabular}{|c|c|c|c|c|}
\hline No. & $\begin{array}{c}\text { Network } \\
\text { Structure }\end{array}$ & $\begin{array}{c}\text { Training } \\
\text { Set MSE } \\
(\mathrm{N} . \mathrm{m})^{2}\end{array}$ & $\begin{array}{c}\text { Validation } \\
\text { Set MSE } \\
(\mathrm{N} . \mathrm{m})^{2}\end{array}$ & $\begin{array}{c}\text { Test Set } \\
\text { MSE } \\
(\mathrm{N} . \mathrm{m})^{2}\end{array}$ \\
\hline 1 & $4-2-1$ & $0.017 !$ & 0.0133 & 0.0184 \\
\hline 2 & $4-4-1$ & 0.0049 & 0.0053 & 0.0116 \\
\hline 3 & $4-6-1$ & 0.0054 & 0.0058 & 0.0216 \\
\hline 4 & $4-8-1$ & 0.0054 & 0.0056 & 0.0265 \\
\hline 5 & $4-10-1$ & 0.0067 & 0.0056 & 0.0202 \\
\hline 6 & $4-12-1$ & 0.0042 & 0.0059 & 0.0210 \\
\hline 7 & $4-2-2-1 *$ & 0.0066 & 0.0057 & 0.0094 \\
\hline 8 & $4-2-4-1$ & 0.0060 & 0.0062 & 0.0116 \\
\hline 9 & $4-4-2-1$ & 0.0067 & 0.0058 & 0.0220 \\
\hline 10 & $4-4-4-1$ & 0.0044 & 0.0055 & 0.0126 \\
\hline 11 & $4-4-6-1$ & 0.0055 & 0.0056 & 0.0220 \\
\hline 12 & $4-6-4-1$ & 0.0025 & 0.0057 & 0.0250 \\
\hline 13 & $4-6-6-1$ & 0.0026 & 0.0053 & 0.0162 \\
\hline 14 & $4-6-8-1$ & 0.0027 & 0.0048 & 0.0135 \\
\hline 15 & $4-8-6-1$ & 0.0011 & 0.0040 & 0.0208 \\
\hline 16 & $4-8-8-1$ & 0.0008 & 0.0050 & 0.0186 \\
\hline 17 & $4-8-10-1$ & 0.0016 & 0.0049 & 0.0194 \\
\hline 18 & $4-10-8-1$ & 0.0007 & 0.0049 & 0.0205 \\
\hline 19 & $4-10-10-1$ & 0.0028 & 0.0057 & 0.0278 \\
\hline 1 & & & \\
\hline
\end{tabular}

* The best network structure.

\subsection{ANNs for Delamination Size Prediction}

Figure 5 shows the schematic diagram of the neural net for predicting the delamination size at drill entrance and drill exit. For each output, six inputs were fed to the network (drill diameter, spindle speed, feed, drill pre-wear, thrust force, and torque). The value of the thrust force and torque that is fed to the ANNs is the average value of the maximum five peaks in drilling process of the hole.

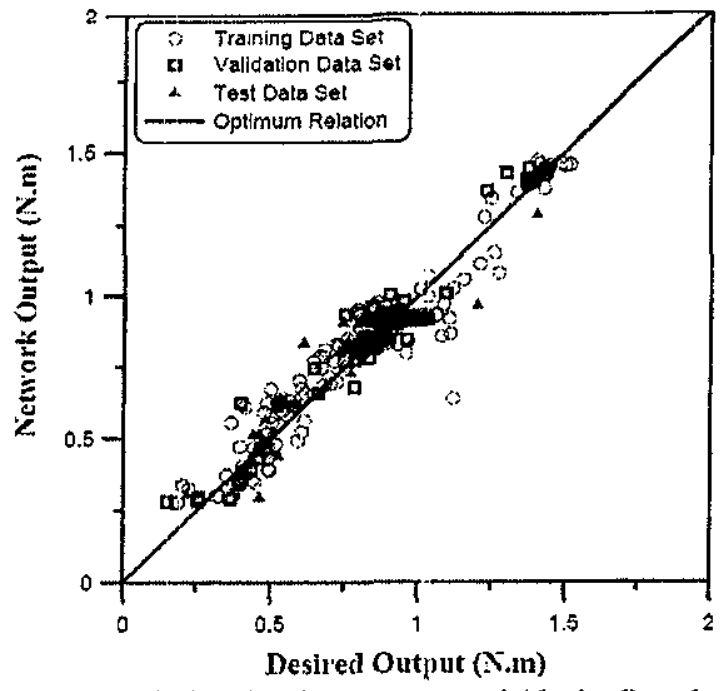

Fig. 4 Relationship between actual (desired) and predicted (output) values of the best obtained network for predicting torque.

To obtain the best neural network structure, twentyseven neural networks were developed by changing both of the number of hidden layers and the number of hidden units within each hidden layer. Tables 3 and 4 represent the tried networks for predicting delamination at drill entry and exit sides respectively. Actually, each network in the Table was obtained by training five times (runs) starting with five different initial weight values, the run and epoch numbers which gave the minimum mean square error (MSE) of the validation sets were chosen as the required net. The criterion of selecting the best net from the tried networks is the minimum mean square of the differences between the measued and the predicted values obtained from the net (MSE), applied for the test data sets. So, from Tables 3 and 4 the best network structures for predicting delamination size at hole entry and exit sides are 6-18-1 (with a MSE of $0.1194 \mathrm{~mm} 2$ ) and 6-6-6-1 (with a MSE of 0.2557 mm2) respectively.

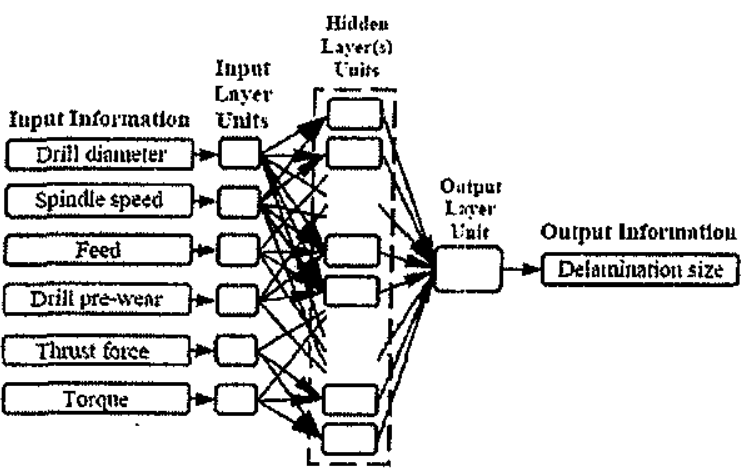

Fig. 5 Schematic diagram of the neural network for predicting delamination size at drill entrance and exit sides. 
Figures 6 and 7 illustrate the relationships between the actual (desired) and predicted (network output) values of the best obtained neural network structures for predicting delamination at hole entry and exit respectively. In order to investigate the performance of the best obtained networks, correlation coefficients between the targets and the corresponding network outputs . (actual-predicted relationship) were estimated. Correlation coefficient is a measure of how well the variation in the outputs is explained by the targets, if the number is equal to 1 , it means that there is a perfect correlation between the targets and the ANNs outputs.

Table 5 shows the values of the correlation coefficients for each of training, validation and test data sets for the developed ANNs. From this Table, it is clear that the values of the correlation coefficients approach to 1 which give strong indication that the obtained ANNs can be used effectively to model and predict thrust force, torque as well as delamination size at both drill entrance and exit sides.

Table 3 Trials for the ANNs for predicting delamination at drill entrance

\begin{tabular}{|c|c|c|c|c|}
\hline No. & $\begin{array}{c}\text { Network } \\
\text { Structure }\end{array}$ & $\begin{array}{c}\text { Training } \\
\text { Set MSE } \\
\left(\mathrm{mm}^{2}\right)\end{array}$ & $\begin{array}{c}\text { Validation } \\
\text { Set MSE } \\
\left(\mathrm{mm}^{2}\right)\end{array}$ & $\begin{array}{c}\text { Test Set } \\
\text { MSE } \\
\left(\mathrm{mm}^{2}\right)\end{array}$ \\
\hline 1 & $6-2-1$ & 0.0196 & 0.0196 & 0.1638 \\
\hline 2 & $6-4-1$ & 0.0140 & 0.0208 & 0.1411 \\
\hline 3 & $6-6-1$ & 0.0082 & 0.0210 & 0.1351 \\
\hline 4 & $6-8-1$ & 0.0055 & 0.0197 & 0.1626 \\
\hline 5 & $6-10-1$ & 0.0058 & 0.0217 & 0.1612 \\
\hline 6 & $6-12-1$ & 0.0031 & 0.0169 & 0.1619 \\
\hline 7 & $6-14-1$ & 0.0026 & 0.0189 & 0.1221 \\
\hline 8 & $6-16-1$ & 0.0028 & 0.0143 & 0.1680 \\
\hline 9 & $6-18-1$ & 0.0018 & 0.0152 & 0.1194 \\
\hline 10 & $6-20-1$ & 0.0018 & 0.0137 & 0.1723 \\
\hline 11 & $6-2-2-1$ & 0.0175 & 0.0276 & 0.1216 \\
\hline 12 & $6-4-4-1$ & 0.0106 & 0.0243 & 0.1286 \\
\hline 13 & $6-4-2-1$ & 0.0101 & 0.0237 & 0.1397 \\
\hline 14 & $6-2-4-1$ & 0.0186 & 0.0302 & 0.1596 \\
\hline 15 & $6-5-5-1$ & 0.0080 & 0.0243 & 0.1824 \\
\hline 16 & $6-4-6-1$ & 0.0128 & 0.0239 & 0.1405 \\
\hline 17 & $6-6-4-1$ & 0.0071 & 0.0243 & 0.1484 \\
\hline 18 & $6-6-6-1$ & 0.0063 & 0.0216 & 0.1781 \\
\hline 19 & $6-6-8-1$ & 0.0048 & 0.0175 & 0.1455 \\
\hline 20 & $6-8-6-1$ & 0.0035 & 0.0172 & 0.1317 \\
\hline 21 & $6-8-8-1$ & 0.0029 & 0.0164 & 0.1655 \\
\hline 22 & $6-10-8-1$ & 0.0025 & 0.0190 & 0.1522 \\
\hline 23 & $6-8-10-1$ & 0.0029 & 0.0187 & 0.1753 \\
\hline 24 & $6-10-10-1$ & 0.0021 & 0.0157 & 0.1495 \\
\hline 25 & $6-12-10-1$ & 0.0017 & 0.0141 & 0.1698 \\
\hline 26 & $6-10-12-1$ & 0.0024 & 0.0187 & 0.1979 \\
\hline 27 & $6-12-12-1$ & 0.0026 & 0.0185 & 0.1230 \\
\hline \hline
\end{tabular}

* The best network structure
Table 4 Trials for the ANNs for predicting delamination at drill exit

\begin{tabular}{|c|c|c|c|c|}
\hline No. & $\begin{array}{c}\text { Network } \\
\text { Structure }\end{array}$ & $\begin{array}{c}\text { Training } \\
\text { Set MSE } \\
\left(\mathrm{mm}^{2}\right)\end{array}$ & $\begin{array}{c}\text { Validation } \\
\text { Set MSE } \\
\left(\mathrm{mm}^{2}\right)\end{array}$ & $\begin{array}{c}\text { Test Set } \\
\text { MSE } \\
\left(\mathrm{mm}^{2}\right)\end{array}$ \\
\hline 1 & $6-2-1$ & 0.1657 & 0.0911 & 0.3899 \\
\hline 2 & $6-4-1$ & 0.1108 & 0.0623 & 0.3978 \\
\hline 3 & $6-6-1$ & 0.1170 & 0.0639 & 0.4225 \\
\hline 4 & $6-8-1$ & 0.1075 & 0.0647 & 0.4052 \\
\hline 5 & $6-10-1$ & 0.1115 & 0.0629 & 0.2851 \\
\hline 6 & $6-12-1$ & 0.0750 & 0.0610 & 0.4552 \\
\hline 7 & $6-14-1$ & 0.0932 & 0.0562 & 0.3296 \\
\hline 8 & $6-16-1$ & 0.0974 & 0.0599 & 0.3315 \\
\hline 9 & $6-18-1$ & 0.0899 & 0.0603 & 0.4750 \\
\hline 10 & $6-20-1$ & 0.0798 & 0.0596 & 0.4670 \\
\hline 11 & $6-2-2-1$ & 0.1366 & 0.0831 & 0.3143 \\
\hline 12 & $6-4-2-1$ & 0.0882 & 0.0627 & 0.3337 \\
\hline 13 & $6-2-4-1$ & 0.1169 & 0.0680 & 0.3414 \\
\hline 14 & $6-4-4-1$ & 0.0778 & 0.0619 & 0.3587 \\
\hline 15 & $6-5-5-1$ & 0.0996 & 0.0605 & 0.2872 \\
\hline 16 & $6-4-6-1$ & 0.1287 & 0.0565 & 0.3838 \\
\hline 17 & $6-6-4-1$ & 0.1131 & 0.0711 & 0.3818 \\
\hline 18 & $6-6-6-1$ & 0.1005 & 0.0605 & 0.2557 \\
\hline 19 & $6-6-8-1$ & 0.0904 & 0.0580 & 0.4711 \\
\hline 20 & $6-8-6-1$ & 0.0958 & 0.0590 & 0.3078 \\
\hline 21 & $6-8-8-1$ & 0.1010 & 0.0614 & 0.2928 \\
\hline 22 & $6-8-10-1$ & 0.0849 & 0.0533 & 0.2990 \\
\hline 23 & $6-10-8-1$ & 0.0712 & 0.0540 & 0.4015 \\
\hline 24 & $6-10-10-1$ & 0.0811 & 0.0515 & 0.3850 \\
\hline 25 & $6-12-10-1$ & 0.0857 & 0.0567 & 0.5438 \\
\hline 26 & $6-10-12-1$ & 0.0935 & 0.0545 & 0.2822 \\
\hline 27 & $6-12-12-1$ & 0.0821 & 0.0624 & 0.4401 \\
\hline
\end{tabular}

* The best network structure

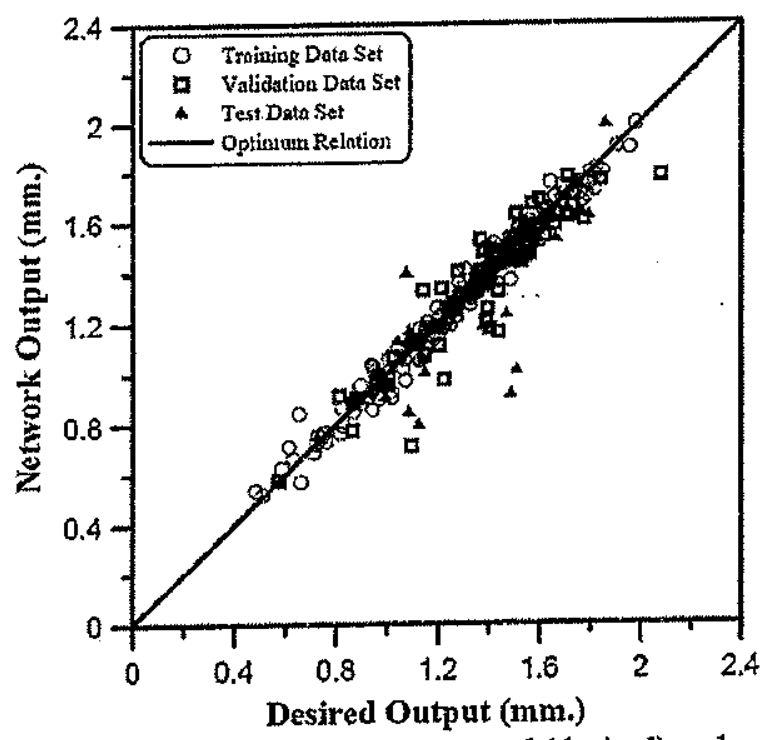

Fig. 6 Relationship between actual (desired) and predicted (output) values of the best obtained network for predicting delamination size at drill entrance. 


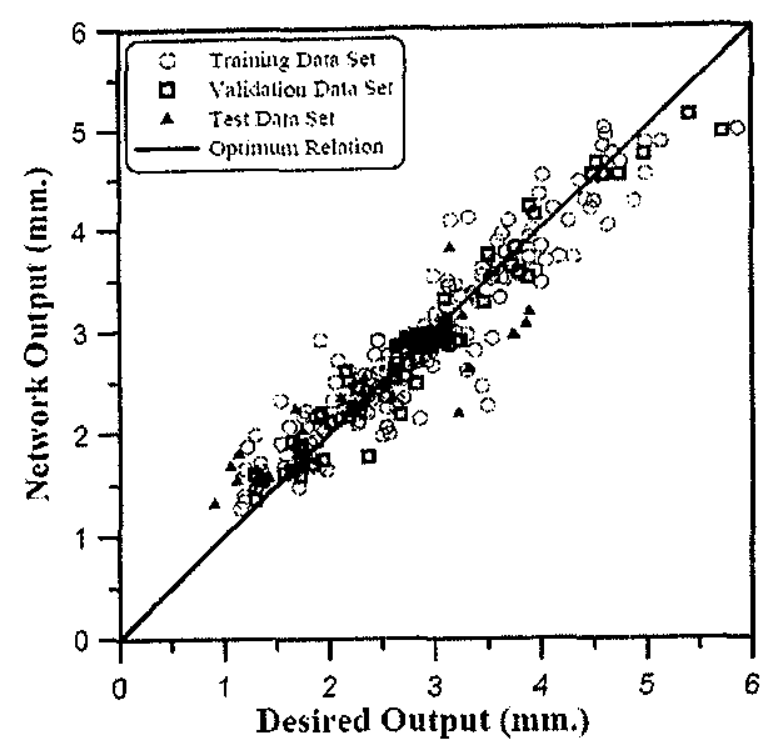

Fig. 7 Relationship between actual (desired) and predicted (output) values of the best obtained network for predicting delamination at drill exit

Table 5 Correlation coefficients for training, validation and test data sets

\begin{tabular}{|c|c|c|c|}
\hline \multicolumn{3}{|c|}{ Correlation coefficients } \\
\hline Best Networks & $\begin{array}{c}\text { Training } \\
\text { Data Set }\end{array}$ & $\begin{array}{c}\text { Validation } \\
\text { Data Set }\end{array}$ & $\begin{array}{c}\text { Test Data } \\
\text { Set }\end{array}$ \\
\hline $\begin{array}{c}\text { Thrust force } \\
(4-4-6-1)\end{array}$ & 0.995 & 0.992 & 0.992 \\
\hline $\begin{array}{c}\text { Torque } \\
(4-2-2-1)\end{array}$ & 0.97 & 0.96 & 0.92 \\
\hline $\begin{array}{c}\text { Drill Entry (6- } \\
18-1)\end{array}$ & 0.99 & 0.92 & 0.78 \\
\hline $\begin{array}{c}\text { Drill Exit } \\
(6-6-6-1)\end{array}$ & 0.94 & 0.98 & 0.87 \\
\hline
\end{tabular}

\section{CONCLUSIONS}

In this work the artificial neural networks technique, with back-propagation training routine, was used for the prediction of delamination size, resulting from drilling GFRE specimens, at drill entrance and exit sides. Secondary ANNs were developed to predict the generated thrust force and torque instead of measuring them every time a delamination prediction process was performed. Several attempts were made to obtain the best structure of these networks. The results obtained lead to the following conclusions;

- The best obtained network structure for predicting thrust force was 4-4-6-1. With a mean-squared error of $685.92 \mathrm{~N}^{2}$ for the test data set.
- The best obtained network structure for predicting torque was 4-2-2-1. With a mean-squared error of $0.0094(\mathrm{~N} . \mathrm{m})^{2}$ for the test data set.

- The best obtained network structure for predicting delamination size at drill entry side was 6-18-1. With a mean-squared error of $0.1194 \mathrm{~mm}^{2}$ for the test data set.

- The best obtained network structure for predicting delamination size at drill exit side was 6-6-6-1. With a mean-squared error of $0.2557 \mathrm{~mm}^{2}$ for the test data set.

- As the correlation coefficients for each of training, validation and test data sets for the developed networks approach to 1 , the best obtained ANNs can be effectively used to model and predict thrust force, torque as well as delamination size at both drill entrance and exit sides.

\section{REFERENCES}

[1] Selmy, A. I., Khashaba, LI. A., El-Sonbaty, I. A. and Megahed, A. A., "Experimental Evaluation of Delamination in Drilling of Fiber Reinforced Composite Materials", Article under publication.

[2] Zhang, Z. and Friedrich, K., "Artificial Neural Networks Applied to Polymer Composites: A Review", Composites Science and Technology, Vol. 63, pp. 2029-2044, (2003).

[3] Ho-Cheng, H. and Dharan, C. K. H., "Delamination During Drilling in Composite Laminates", Transactions of the ASME, Journal of Engineering for Industry, Vol. 112, pp. 236239, August (1990).

[4] Jain, S. and Yang, D. C. H., "Effects of Feedrate and Chisel Edge on Delaritination in Composites Drilling", Transactions of the ASME, Journal of Engineering for Industry, Vol. 115, pp. 398-405, November (1993).

[5] Jain, S. and Yang, D. C. H., "Delamination-Free Drilling of Composite Lacninates", Transactions of the ASME, Journal of Engineering for Industry, Vol. 116, pp. 475-481, November (1994).

[6] Stone, R. and Krishnamurthy, K., "A Neural Network Thrust Force Controller to Minimize Delamination During Irilling of GraphiteEpoxy Laminates", International Journal of Machine Tools \& Manufacture, Vol. 36, No. 9, pp. 985-1003, (1996).

[7] Sadat, Abdul B., "Prediction of Delamination Load in Drilling of Graphite/Epoxy Composites", ASME, Petroleum Division, Vol. 75, No. 3, pp. 21-27, (1996).

[8] Enemuoh, U. E., El-Gizarvy, A. S. and Okafor, A. C., "Neural Network Based Sensor Fusion for On-line Prediction of Delamination and Surface 
Roughness in Drilling AS4/PEEK Composites", Technical Paper-Society of Manufacturing - Engineers, MS, n MS99-187, pp. MS99-187-1 MS99-187 - 6, (1999).

[9] Chakraborty, D., "Artificial Neural Network Based Delamination Prediction in Laminated Composites", Materials and Design, Vol. 26, pp. 1-7, (2005).

[10] Sardiñas, R. Q., Pedro Reis and Davim, J. P., "Multi-objective Optimization of Culting Parameters for Drilling Laminate Composite Materials by Using Genetic Algorithms", Composites Science and Technology Vol. 66, pp. 3083-3088, (2006).

[11]Srinivasa Rao, B., Rudramoorthy, R., Srinivas, S. and Nageswara Rao, B., "Effect of Drilling Induced Damage on Notched Tensile and Pin Bearing Strengths of Woven GFR-Epoxy Composites", Materials Science and Engineering A, Vol. 472, pp. 347-352, (2008).

[12] Karnik, S. R., Gaitonde, V. N., Campos Rubio, J., Esteves Correia, A., Abrão, A. M. and Paulo Davim, J., "Delamination Analysis in High Speed Drilling of Carbon Fiber Reinforced
Plastics (CFRP) Using Artificial Neural Network Model", Materials and Design, Vol. 29, pp. 1768-1776, (2008).

[13] Abu-Mahfouz, I., "Drilling wear detection and classification using vibration signals and artificial neural network", International Journal of Machine Tools and Manufacture, Vol. 43, pp. 707-720, (2003).

[14] Crystic Monograph No.2: Polyester Handbook, Crystic Research Centre, England, (1971).

[15] Swingler, K., "Applying Neural Networks: A Practical Guide", Academic Press Inc., London, (1996).

[16] Haykin, S., "Neural Networks: A Comprehensive Foundation", Prentice-Hall Inc., USA, Second Edition, (1999).

[17] Hertz, J., Krogh, A. and Palmer, R. G., "Introduction to the Theory of Neural Computation", Addison-Wesley Publishing Company Inc., USA, (1991).

[18] Neurosolutions software, version 5 , www.nd.com. 